\title{
Biopsy and vascularization: testicular tissue removal and prevention of hemorrhagies related to the main vessels
}

\author{
Patricia Z. Deh ${ }^{1 *}$, Okon AJL ${ }^{1}$, Adjoua-N' goran $\mathrm{MF}^{2}$, Tré-Yavo $\mathrm{M}^{1}$ and Kokoua $\mathrm{A}^{2}$
}

*Correspondence: dehzpatricia@yahoo.fr

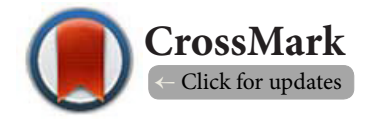

'Laboratory of Histology-Embryology and Cytogenetic, UFR-Medical Sciences, Félix Houphouët-Boigny University, Abidjan, Côte d'Ivoire.

${ }^{2}$ Laboratory of Anatomy and Organogenesis, UFR-Medical Sciences, Félix Houphouët-Boigny University, Abidjan, Côte d'Ivoire.

\begin{abstract}
Purpose: the objective of the work is to determine the testicular regions favorable for the realization of a testicular biopsy without damaging the important vessels.

Material and Methods: 8 left and right testes were collected from 3 immature Wistar rats and 1 adult control, aged 15, 25 and 40 days for the young rats and 7 months for the adult. The testes were taken under inhalation anesthesia. The testes were examined by eye and the images were obtained from a digital camera.

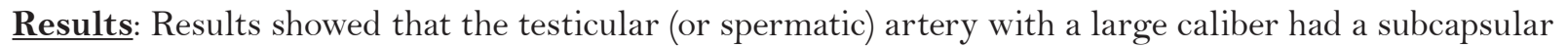
arrangement. It was tortuous and followed the anterior edge of the testicle from the upper pole to the lower pole. As that vessel passed along this place it formed an arterial handle and ascended along the posterior edge. The arrangement of this artery was identical for all populations of rats. Very small vessels were observed beneath the internal surface of the albuginea of the testis mainly from the lateral areas of the testis. They had transverse, horizontal and oblique directions and which intensified with the age of the animals.

Conclusion: Anatomically, the results of this study highlight the situation and caliber variability of the superficial vessels of the testis and the importance of the testicular artery. Clinically, they could be useful for testicular biopsy, we suggest that it be practiced away from the large vessels, that is to say in the lateral areas of the testicle.
\end{abstract}

Keywords: Testicular vessels, Testicular biopsy, Testis, Wistar rats

\section{Introduction}

The testicles are the male genital glands that are found in the scrotum at the base of the penis. They produce the spermatozoa necessary for reproduction, and hormones such as testosterone, the main male sex hormone that stimulates development and testicular function [1].

The vascularization of the testicles consists of all the vessels irrigating their regions. It mainly comprises the spermatic or testicular arteries that originate from the abdominal aorta and the spermatic or testicular veins from the spermatic venous plexus, also called pampiniform plexus $[2,3]$. At the histofunctional level, the testicular artery forms an internal dense arterial network that maintains thermoregulation of the testis with the pampiniform plexus [4] and has a nutritional role
[5]. It causes a rhythmic variation in arterial blood flow and intervenes in the regulation of blood flow inside the testicle [6]. The testicular artery has an endocrine role through the transfer of testosterone [7]. In addition, studies show that it is the artery of fertility $[8,9]$.

Testicular biopsy involves collecting a tissue sample from one or both testes on a living organism [10]. There are two different methods for testicular biopsy, which are percutaneous biopsy and open biopsy. The first one is to insert a fine needle into the skin. A syringe is placed at the tip of the needle for the removal of testicular tissue. It is also referred to as fine needle biopsy. Drill biopsy is a variation of this technique. It is made with a hollow spring needle to take a piece of tissue of cylindrical shape. 
The second is also called surgical biopsy. It consists in making an opening in the skin. An incision is also made in the testicle and a small sample of tissue is taken from the opening. The incision is closed with stitches.

Testicular biopsy is a critical examination to diagnose male infertility. It is used to assess the condition of the tissues of the sampled area by histological analysis in a diagnostic purpose such as cell analysis to study spermatogenesis and to determine the cause of infertility of a man $[11,12]$. Thus, this gesture is practiced in men with azoospermia or absence of spermatozoa in the semen in particular. In the case of vas deferens obstruction, the biopsy is performed to collect sperm for intracytoplasmic sperm injection (ICSI). In this case, it will be realized if spermatozoa are produced in the testicles, but are not present in the sperm. When examination of the testes by palpation or ultrasound has revealed the presence of a mass, the biopsy can be used to determine the cause of this testicular mass, whether it is a cancerous mass or not [13].

However, accidents can arise during the testicular biopsy and hinder more on less operative maneuvers or have consequences. They can be consulted on the cutting instrument on an area of which it does not know the anatomical organization of the arterial and venous vessels. This could hurt important vessels and cause a hemorrhagic memory $[11,14,15]$.

Despite the importance of the testicular arteries, numerous observations indicate its lesion during surgical procedures involving the testis and its environment (orchidopexy and cryptorchidism treatments, varicocele, testicular torsion, inguinal hernia) [16-18]. These lesions are responsible for decreased arterial flow in the testis and necrosis $[\mathbf{8}, \mathbf{9}]$, testicular atrophy $[18,19]$ and infertility $[8,9,20]$.

Seen the procedure used during testicular biopsy, the objective of this work is to determine favorable testicular regions for the realization of a testicular biopsy without damaging important vessels in the Wistar rat, animal model of the testicular vascularization which is similar to that of the human [21].

\section{Material and methods \\ Animals}

The biological material involved 8 testes (left and right) of 3 immature Wistar rats (Rattus norvegicus) aged 15, 25 and 40 days followed by 1 adult rat aged 7 months (Pet shop of UFRBiosciences, Félix Houphouët-Boigny University of Abidjan in Côte d'Ivoire).

The rats were bred in the plastic cages, at room temperature. The daily lighting corresponds to 12 hours of light. They were fed (Livestock feed company in Côte d'Ivoire or FACl) and watered with ad-libitum drinking water.

\section{Taking of testes}

The dissection was performed under general anesthesia with ether by inhalation under a vat. The right and left epididymo-testicular blocks were removed after an inguinal incision. Then, the gonads were cleared of their epididymis and scrotal ligament.

\section{Macroscopic observation of superficial vessels and photography}

The macroscopic observation of testes belonging to each age was performed. The organs examined with the naked eye. This examination gives us information on the appearance of the superficial vessels of the testes. It is necessary to determine the situation of the vessels and the variation of the caliber.

The images were obtained using a digital camera (Canon 12 Megapixels) [3].

\section{Results and Discussion}

The results are given according to the macroscopic observation of the superficial vessels at the anterior, upper, lower and lateral sides of the testes (Figures 1-4).

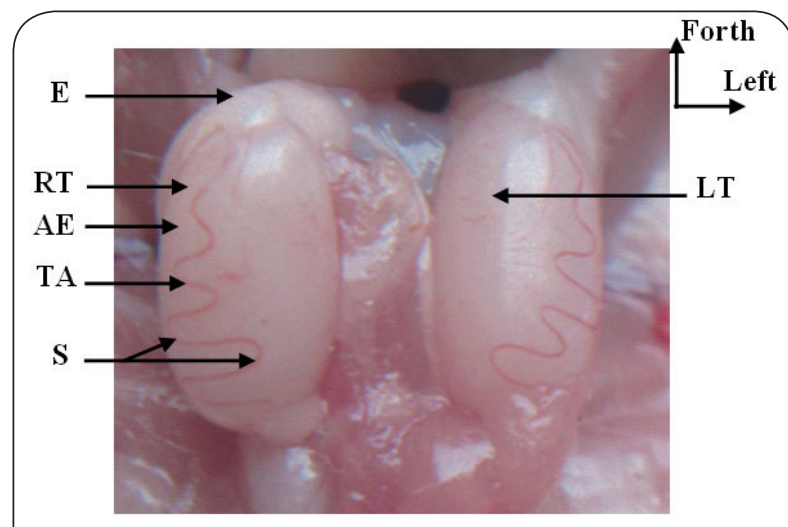

Figure 1. Photograph of left and right testes showing testicular arteries at the anterior edge (AE) of 15-day-old rat. The right and left testicular arteries (TA) with a large caliber show similar shapes in the image. They travel along the anterior edge of the testicles with a sinuous path from the upper to the lower extremities. Epididymis (E), Sinuosities of the testicular artery (S), Left testicle (LT), Right testicle (RT).

In this work, it was necessary to define advantageous testicular regions for the testicular biopsy in the rat, an animal model whose testicular vascularization is similar to that of the human [21] from the macroscopic observation of the superficial vessels of the testicle through the albuginea. This is available to the naked eye because it is transparent in the rat. However, the albuginea is opaque in man, making it impossible to visualize the superficial main arteries $[20,22]$.

We received the testicular artery with a big caliber on the surface of the anterior edge of the testis in all populations of rats. It was tortuous and followed the anterior edge from the upper pole to the lower pole. Along this place, it forms an arterial handle and ascended along the posterior edge. This artery appears to be the "artery of the anterior edge" already described $[9, \mathbf{1 4}]$. This artery arrangement was identical for all 

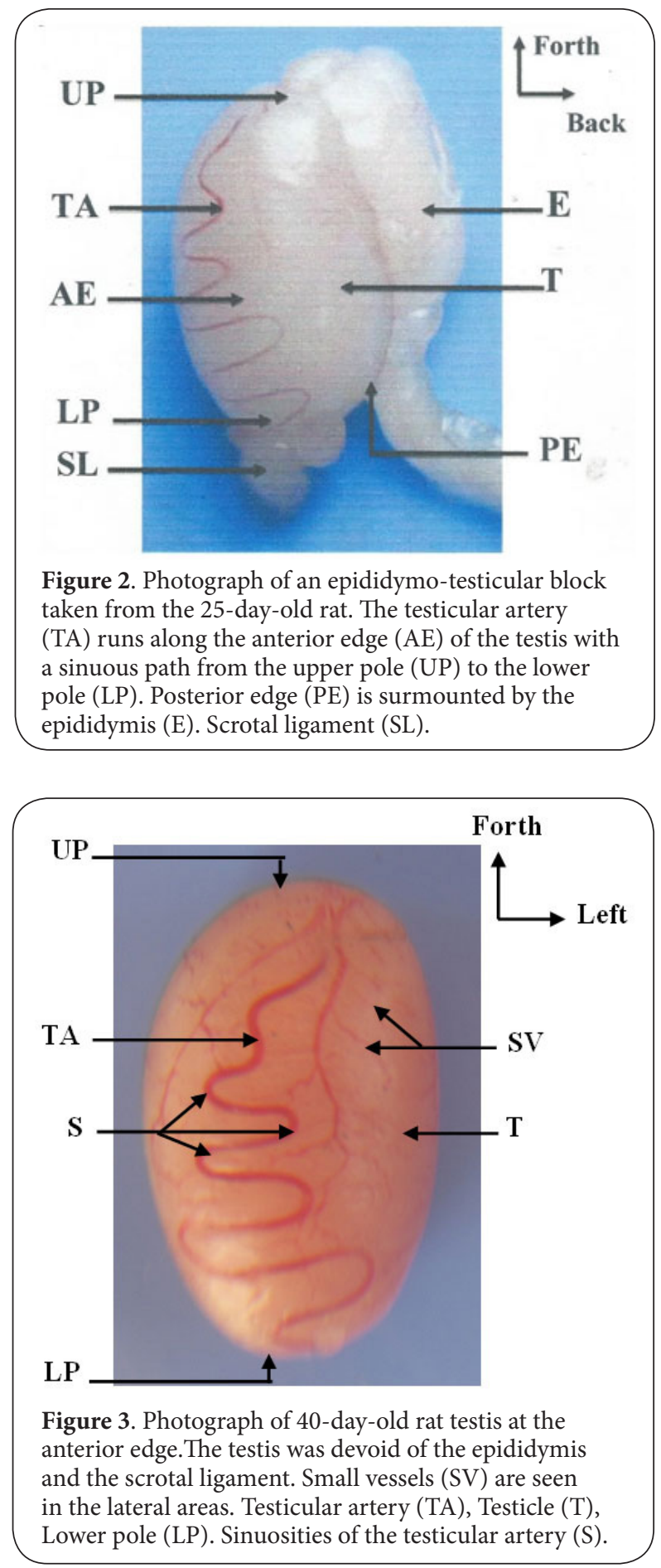

populations of rats.

We also observed the very small vessels under the internal surface of the testicular albuginea in the lateral areas of the testicles. They had transverse, horizontal and oblique directions and intensified with the age of the animals. Sub-capsular vessels in similar arrangements were described from angiography in the rat [23], the rabbit [24], the human $[25,26]$ and the

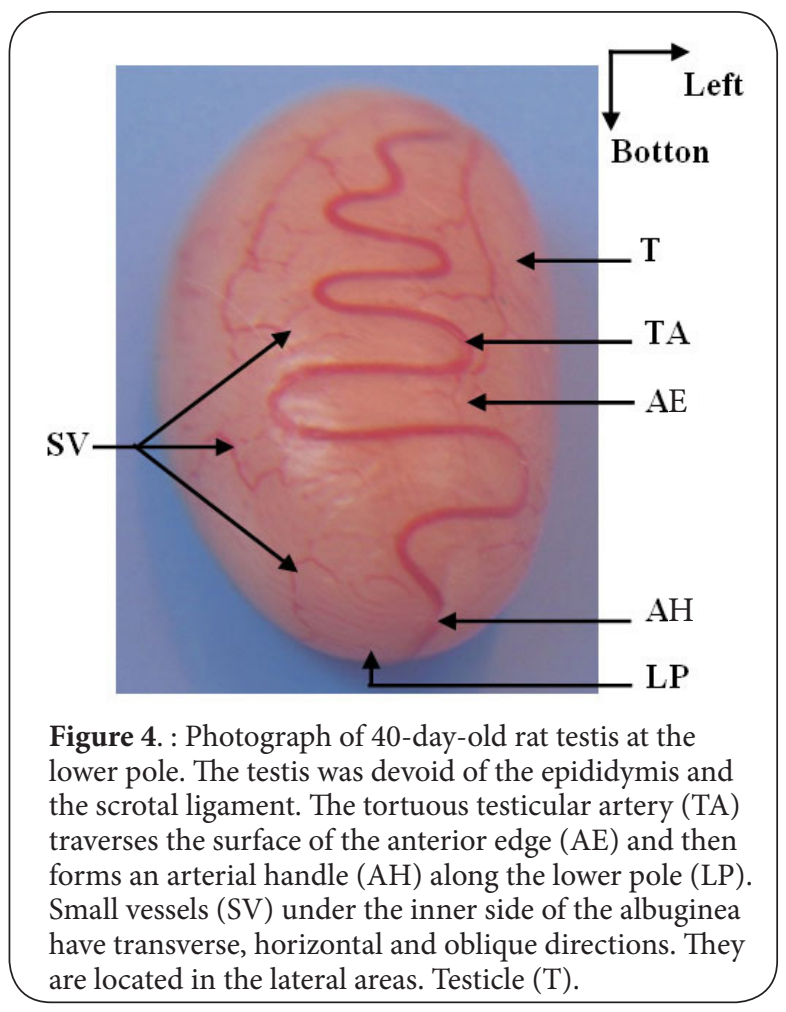

bovine [17]. According to these sources, this device is used to form a layer called vascular tunic located on the deep side of the albuginea. It consists of arteries, veins and lymphatic vessels spread out on the surface of the testicle $[17,24,25]$.

The macroscopic observation through the albuginea did not allow us to bring the details on the vessels to the surface of the posterior edge because the testicle is surmounted by the epididymis at this place (Figure 2). The take-off of this structure resulted in the destruction of the vessels. However, several studies of testicular vascularization have shown that large veins drained peripherally into the posterior edge region $[\mathbf{9}, \mathbf{1 4}, \mathbf{2 4}]$.

No vessels were seen on the external surface of the testis during macroscopic examination. The most peripheral vessels were those housed under the internal surface of the albuginea, which have been described above.

Histologically, work carried out in 2013 studied the intratesticular course of the testicular artery by transverse serial sections in the rat [14] and its 3D reconstruction from serial histological sections in the rat was made $[3,15]$. The results of this work revealed that the testicular artery perforated the testicle by the upper pole at the level of the hilum. This intratesticular artery divided into two branches: a tortuous anterior branch, called the "anterior edge artery," and a regular posterior branch, called the posterior edge artery. These two branches of division were terminal. They had a subcapsular arrangement, and descended to the lower pole of the testicle. At this level, the artery of the posterior edge terminated before the artery of 
Deh et al. Journal of Histology \& Histopathology 2018,

http://www.hoajonline.com/journals/pdf/2055-091X-5-1.pdf

doi: 10.7243/2055-091X-5-1

the anterior edge. The last one traveled along the lower pole forming an arterial handle, and ascended along the posterior edge to end in the region of the lower extremity $[3,14,15]$.

Studies of testicular vasculature demonstrated morphological stability in the intragonadic branches of the testicular artery in the rat $[3,21]$. Indeed, in the testicle of this rodent, a type of arterial arrangement encountered in adults is already present at birth $[3,14,15,23]$.

Clinically, testicular biopsy because of the invasive nature of this procedure and its risk of serious complications, numerous studies in various animal species and in humans have focused on the precautions to be taken during this procedure without damaging the testicles [27-29]. These studies evaluated various techniques, including percutaneous biopsy and surgical biopsy. In the testis, hemorrhage, necrosis and testicular atrophy have been reported after surgical biopsies in stallions $[30,31]$.

The interest of testicular biopsy is mainly its use in the management of male infertility, for diagnosis and treatment.

Repeated biopsies are sometimes performed to obtain sperm for ICSI, to evaluate a testicular tumor, or to detect histological changes because of the progression of hypospermatogenesis [11,32].

It should be noted that an ICSI with a testicular biopsy is indicated in the case where a total absence of spermatozoa in the sperm (azoospermia) is verified and that there is a production of spermatozoa by the testes and then a problem of blocking or transport of spermatozoa occur. This technique is also applied in men with congenital absence of vas deferens or vasectomy. In this case, the testicular biopsy represents the only way to demonstrate the presence of spermatozoa.

As the testis are highly vascularized, the main potential complication of testicular biopsy is hemorrhage $[31,33]$. Indeed, while repeating these invasive procedures, the risk of hemorrhage is increased [34,35].

To minimize these risks, tissue samples should be taken from low vascular areas $[34,36]$. In the rat testis, these areas were identified in the lateral regions of the testis. The realization of a biopsy at the anterior and posterior edges of the gonads could damage the main branches of the testicular artery and cause immediate hemorrhage. A similar study also looked for favorable areas for biopsy of the stallion testis [31]. This study suggested that the sites of the branches of the testicular arteries should be determined before realizing a testicular biopsy.

The testicular biopsy could be completed at the Doppler for an exploration of arterial branches. The anatomical precisions found by this study could codify the behavior of the operator.

\section{Conclusion}

Anatomically, the results of this study highlight the situation and caliber variability of the superficial vessels of the testis and the importance of the testicular artery. Clinically, they could be useful for testicular biopsy, we suggest that it be practiced away from large vessels that is the lateral areas of the testis.

\section{Competing interests}

The authors declare that they have no competing interests.

Authors' contributions

\begin{tabular}{|l|c|c|c|c|c|}
\hline Authors' contributions & PZD & OAJL & ANMF & TYM & KA \\
\hline Research concept and design & $\checkmark$ & -- & -- & $\checkmark$ & $\checkmark$ \\
\hline Collection and/or assembly of data & $\checkmark$ & -- & -- & -- & -- \\
\hline Data analysis and interpretation & $\checkmark$ & -- & -- & -- & -- \\
\hline Writing the article & $\checkmark$ & -- & -- & -- & -- \\
\hline Critical revision of the article & $\checkmark$ & $\checkmark$ & $\checkmark$ & $\checkmark$ & $\checkmark$ \\
\hline Final approval of article & $\checkmark$ & $\checkmark$ & $\checkmark$ & $\checkmark$ & $\checkmark$ \\
\hline Statistical analysis & -- & -- & -- & -- & -- \\
\hline
\end{tabular}

\section{Acknowledgement}

The authors acknowledgement the Histology-EmbryologyCytogenetic Laboratory and Anatomy-Organogenesis Laboratory of Félix Houphouët-Boigny University of Côte d'Ivoire which ones contributed to this work.

Publication history

EIC: Gaetano Giuseppe Magro, University of Catania, Italy. Received: 07-Aug-2017 Final Revised: 10-Oct-2017

Accepted: 24-Dec-2017 Published: 02-Jan-2018

\section{References}

1. Shiraishi $\mathrm{K}$ and Matsuyama H. Gonadotoropin actions on spermatogenesis and hormonal therapies for spermatogenic disorders [Review]. Endocr J. 2017; 64:123-131. | Article | PubMed

2. Plainfossé MC. Genitals. In: Color ultrasound in visceral and peripheral practice. 3rd Edition. Paris: Masson. 1997; 218-219.

3. Deh ZP. Intragonadic course of testicular artery: histological and threedimensional approaches inWistar rats. [Doctorate of Unique Thesis], Abidjan, UFR-Med. Sci. Univ. FHB. Sci. FHB.Univ. 2014; 26: 163.

4. Terayama $H$, Naito $M$, Nakamura $Y$, limura $A$, Itoh $M$, Tamatsu $Y$ and Shimada K. Corrosion casts of convoluted testicular arteries in mice and rats. Arch Androl. 2005; 51:471-80. | Article | PubMed

5. Collin O, Zupp JL and Setchell BP. Testicular vasomotion in different mammals. Asian J Androl. 2000; 2:297-300. I Article I PubMed

6. Heinze W and Ptak W. Comparative morphological studies on the vascular systems of testes in cattle, swine, horse and dog under functional conditions. Arch Exp Veterinarmed. 1976; 30:669-85. | PubMed

7. Murakami T, Uno Y, Ohtsuka A and Taguchi T. The blood vascular architecture of the rat testis: a scanning electron microscopic study of corrosion casts followed by light microscopy of tissue sections. Arch Histol Cytol. 1989; 52:151-72. I PubMed

8. Kokoua A, Tré-Yavo M, Santos KAN, Homsy Y, Mobiot ML and Gnanazan Bi N'guessan G. Testicular artery value: histofunctional and comparative approaches in young rat and rat. Morphol. 2004; 88: 31- 4.

9. Tré-Yavo M. Internal vascularization of the testis: histological and functional approaches in rat. [Doctorate of Unique Thesis], Abidjan, UFRMed. Sci. FHB. Univ. 2004; 2:130.

10. Friedler S, Raziel A, Strassburger D, Schachter M, Soffer Y and Ron-El R. Factors influencing the outcome of ICSI in patients with obstructive and non-obstructive azoospermia: a comparative study. Hum Reprod. 2002; 17:3114-21. I PubMed

11. Amer M, Ateyah A, Hany R and Zohdy W. Prospective comparative study between microsurgical and conventional testicular sperm extraction in non-obstructive azoospermia: follow-up by serial ultrasound examinations. Hum Reprod. 2000; 15:653-6. I PubMed

12. Hussein A. Evaluation of diagnostic testis biopsy and the repetition of testicular sperm extraction surgeries in infertility patients. Fertil Steril. 2013; 100:88-93. | Article | PubMed 
Deh et al. Journal of Histology \& Histopathology 2018,

13. Dieckmann KP, Anheuser P, Gehrckens R, Wilczak W, Sauter G and Hoflmayer D. Pure testicular seminoma relapsing late with somatic type malignancy. Case Rep Oncol Med. 2017; 2017:2457023. | Article | PubMed Abstract | PubMed FullText

14. Deh ZP, Tré-Yavo M, Kokoua A, Yao GV and Sakho SS. The testicular artery: astudy of the intratesticular course by transverse serial sections in rat. JAMO. 2013; 7: 44-49.

15. Tré-Yavo M, Deh ZP, Kokoua A, Yao GV and Ehouman A. Morphology of the intratesticular arteries: a 3D reconstruction approach by transverse histological serial sections in rat. JAMO. 2013; 7:16-21.

16. Mostafa T, Labib I, El-Khayat Y, El-Rahman El-Shahat A and Gadallah A Human testicular arterial supply: gross anatomy, corrosion cast, and radiologic study. Fertil Steril. 2008; 90:2226-30. | Article I PubMed

17. Polguj M, Sopinski M, Jedrzejewski K, Bolanowski W and Topol M. Angioarchitecture of the bovine tunica albuginea vascular complex--a corrosive and histological study. Res Vet Sci. 2011; 91:181-7. | Article | PubMed

18. Dilek ON. Hernioplasty and testicular perfusion. Springerplus. 2014; 3:107. | Article | PubMed Abstract | PubMed FullText

19. Salman FT and Fonkalsrud EW. Effect of spermatic vascular division for correction of high undescended testis on testicular function. Am J Surg. 1990; 160:506-10.

20. Jarow JP. Intratesticular arterial anatomy. J Androl. 1990; 11:255-9. | Article | PubMed

21. Kormano $\mathrm{M}$ and Suoranta $\mathrm{H}$. Microvascular organization of the adult human testis. Anat Rec. 1971; 170:31-9. I Article I PubMed

22. De Kretser MD, Loveland K and O’Bryan M. Spermatogenesis: in Jameson JL, De Groot J Endocrinol: Adult and pediatric. Elsevier Health Sciences, Edit 7. Chapter. 2015; 136:2326-2329.

23. Kormano M. An angiographic study of the testicular vasculature in the postnatal rat. Z Anat Entwicklungsgesch. 1967; 126:138-53. | PubMed

24. Rajtova $V$ and Danko J. Vasculature of testis, epididymis and ductus deferens of rabbit. Acta Vet Brno. 2001; 70:3-7.

25. Clavert $P$, Maillot $C$ and Clavert $A$. Testicular angioarchitecture: review of the literature and surgical implications. Androl. 1998; 8:57-61.

26. Middleton WD and Bell MW. Analysis of intratesticular arterial anatomy with emphasis on transmediastinal arteries. Radiology. 1993; 189:15760. | Article | PubMed

27. Faber NF and Roser JF. Testicular biopsy in stallions: diagnostic potential and effects on prospective fertility. J Reprod Fertil Suppl. 2000; 31-42. PubMed

28. Carluccio A, Zedda MT, Schiaffino GM, Pirino S and Pau S. Evaluations of testicular biopsy by tru-cut in the stallion. Vet Res Commun. 2003; 27 Suppl 1:211-3. I PubMed

29. Pearson LK, Rodriguez JS and Tibary A. How to obtain a stallion testicular biopsy using a spring-loaded split-needle biopsy instrument. Proc. Am. Ass. Equine Pract. 2011; 57:219-225.

30. Varner DD. Diseases and management of breeding stallions. A.V.P, Goleta. 1991; 93.

31. Pozor MA and Harnik S. Lateral branches of the testicular artery affect testicular shape in adult stallions. J. Equine. Vet. Sci. 2016; 36:90-96. | Article

32. Nieschlag E, Behre HM, Wieacker P, Meschede D, Kamischke A and Kliesch S. Disorders at the testicular level. In: Nieschlag E, Behre HM and Nieschlag S.Androl.Male reproductive health and dysfunction, $3^{\text {rd }}$ ed, Eds: Springer-Verlag, Berlin, Heidelberg. 2010; 94-38.

33. Smith JA. Biopsy and the testicular artery of the horse. Equine Vet J. 1974; 6:81-3. | Article | PubMed

34. Hunt WL and Foote RH. Effect of repeated testicular biopsy on testis function and semen quality in dogs. J Androl. 1997; 18:740-4. | Article | PubMed

35. Kirsten JC, Janosek-Albright A, Peter N. Schlegel B and Ali A et al. Testis sperm extraction. Asian J Urol. 2015; 2:79-84.

36. Binsaleh S, Alhajeri D and Madbouly K. Microdissection testicular sperm extraction in men with nonobstructive azoospermia: Experience of King Saud University Medical City, Riyadh, Saudi Arabia. Urol Ann. 2017; 9:136-140. | Article | PubMed Abstract | PubMed FullText

\section{Citation:}

Deh PZ, Okon AJL, Adjoua-N’ goran MF, Tré-Yavo M and Kokoua A. Biopsy and vascularization: testicular tissue removal and prevention of hemorrhagies related to the main vessels. J Histol Histopathol. 2018; 5:1. http://dx.doi.org/10.7243/2055-091X-5-1 